\title{
Toxicity Profile of Karuho Poison on the Brain of Wistar Albino Rats
}

\author{
Samuel Kule Kyolo', Godfrey S. Bbosa ${ }^{1 *}$, John Odda ${ }^{1}$, Aloysius M. Lubega ${ }^{1}$, \\ Ntabe Namegabe Edmond ${ }^{2}$ \\ ${ }^{1}$ Department of Pharmacology \& Therapeutics, Makerere University College of Health Sciences, Kampala, Uganda \\ ${ }^{2}$ Department of Medicine, Faculty of Medicine, Université Libre des Pays des Grands Lacs (ULPGL), Goma City, DR Congo \\ Email: *godfossa@gmail.com
}

How to cite this paper: Kyolo, S.K., Bbosa, G.S., Odda, J., Lubega, A.M. and Edmond, N.N. (2018) Toxicity Profile of Karuho Poison on the Brain of Wistar Albino Rats. Neuroscience \& Medicine, 9, 63-80. https://doi.org/10.4236/nm.2018.92008

Received: March 3, 2018

Accepted: June 12, 2018

Published: June 15, 2018

Copyright $\odot 2018$ by authors and Scientific Research Publishing Inc. This work is licensed under the Creative Commons Attribution International License (CC BY 4.0).

http://creativecommons.org/licenses/by/4.0/

\begin{abstract}
Various forms of Karuho poisoning are a common traditional mystery and a public health challenge in Goma city, North Kivu in DRC practiced by unscrupulous people. Its signs and symptoms are commonly mistaken by local communities and medical world with those of tuberculosis, HIV/AIDS and typhoid fever; with neurological and psychological symptoms. Study investigated sub-acute toxicity of Karuho poison on brain of Wistar albino rats. Laboratory based experimental study was conducted at Department of Pharmacology \& Therapeutics, Makerere University College of Health Sciences. A total of 4 Karuho poisons (OMGKRP, DLNKRP, CHKRP and BHKRP) were screened for acute and sub-acute toxicity. Fifty animals, 10 in each group were daily dosed for 28 days with $1 \mathrm{mg}, 5 \mathrm{mg}, 20 \mathrm{mg}$ and $5000 \mathrm{mg} / \mathrm{kg}$ bwt of OMGKRP (most active following screening) and normal saline for control group using OECD 407 and NIH 2011 guidelines. Behavioral changes were noted. Histopathological changes in brain regions were analyzed. Treated rats by OMGKRP, most active Karuho poison, were associated with sign of depression, piloerection and shortness of breath. Histopathological changes revealed moderate diffuse congestion and mononuclear inflammatory cells infiltration (plasma cells, lymphocytes and macrophage) in cerebral region with severe inflammation observed in meninges of cerebellum. OMGKRP poison induced inflammation of meninges of cerebellar region of brain.
\end{abstract}

\section{Keywords}

Karuho Poison, OMGKRP, Brain Tissue and Sub-Acute Toxicity

\section{Introduction}

Karuho poisoning is a common public health problem in Goma city in Eastern 
Democratic Republic of Congo (DRC) and in the neighboring country Rwanda. It has created fear in various communities as revenge is a common practice during the ethnic conflicts that has ravaged the countries for long [1] [2]. According to Nsapu (2014) [2], "deep divisions between these tribal communities-and an overall culture of mistrust in a region that is home to more than 40 rebel groups-contributes to the widespread belief that people poison one another as a revenge tool". The country has been affected by political conflicts for more than 15 years [3] and these conflicts usually involve poisoning of others by different types of poisons some of which are locally made potion by the name Karuho. Goma city and its surrounding areas, located in the Eastern part of DRC; have been affected by various types of homicide, an act of human being causing deliberate death of another human being according to United Nations Office on Drug and Crime [4]. This homicide includes army confrontations, rape, massacre, Karuho poisoning and many other war crimes. Different varieties of Karuho poisons are commonly used to poison people and the effects observed can be acute or chronic depending on the dose and the type of poison used. The poisons are reported to be made locally from the available natural products including venoms derived from chameleon and toad/frog skin, blue headed Agama lizard, human placenta or some rare plant extracts such as Datura stramonium and some minerals like arsenic, mercury and cadmium and many others [1] [2] [5]. According to the survey by Uwizeye (2004) [6], on knowledge of Karuho poison by the various communities of Goma City; it has been reported that about $99.1 \%$ of people living in the city have knowledge on Karuho poison and the poisoning, and of these about $85.1 \%$ have been directly or indirectly fall a victims of Karuho poisoning [6].

According to Simisi (2000) [7] and Uwizeye (2004) [6], poisoned individuals by the different type of Karuho poison, are usually reported to present with either acute or chronic signs/symptoms depending on the ingested dose. The acute signs and symptoms reported depend on the type of Karuho poison ingested and they include nausea and vomiting with atrocious pain of epigastrium, agitation, profuse sweat, and shortness of breath, loss of consciousness, hematemesis, convulsion and death in few hours [7]. While chronic Karuho poisoning has been reported to present with signs and symptoms including weight loss that evolves toward cachexia, faint, cough, chest discomfort, fever, effort dyspnea, nausea with ptyalism or sialorrhea (excessive production of saliva), and change in hair color [7]. And usually these signs/symptoms are commonly confused with those of tuberculosis (TB), typhoid fever (TF), cancer, HIV/AIDS and many other chronic conditions/ diseases hence causing a delay in seeking medical attention since such affected individuals think that they have been poisoned by Karuho. Among the local communities of Goma city, there is phobia of Karuho poison and this problem is a real social threat and has changed the behaviors of many people towards their neighbors within the communities as well as the treatment seeking behaviors for many other medical conditions like TB, 
HIV/AIDS, malaria and various types of cancers [6]. And also the orthodox medical practitioners have continued to ignore Karuho claim, due to lack of scientific evidence. And as a consequence, many people in eastern DRC die of preventable and treatable diseases or delay in seeking medical treatment as they consult traditional healers first with the belief that they have been poisoned by Karuho poison and that they can only be cured by traditional healers meanwhile as the condition worsens [5].

Many of these people as reported by the Integrated Regional Information Networks (IRIN), that more than 90 percent of HIV-infected patients go to the hospital when they are in World Health Organization (WHO) HIV stage 3 or 4 due to delay to seek treatment as they think that they have been poisoned by Karuho [5]. Karuho poisoning also has been reported to present with mental signs and symptoms including abnormal behavior change, depression, motor and other neurological changes. And these Karuho poison effects on the brain could be due to the presence of active compounds in the raw materials that are used including chameleon heads, toad skin and plant extracts [2]. Also the country is rich in natural forests and medicinal plants with various pharmacological activities, some of which are used in Karuho poison preparation and thus possess various effects on the brain [8] [9] [10], thus causing the effects observed during the poisoning. Also many medicinal plants some of which may be used in Karuho concoction contain active compounds such as alkaloids, amino acids, and phenolic and polyphenolic compounds and these compounds have been reported to have a stimulating or depressive activity on the CNS [11] [12]. Some of the reported medicinal plants with neurotoxic effects that have been reported include Alocasia macrorrhiza, A. odora [13], Albizia myriophylla Benth [14] and many others. Also medicinal plants are commonly used in Karuho poison preparation and some of these plants including Cymbopogon species, Artemisia species, Cynanchum argel delile, Equisetum, and Vitex agnus-castus and many others have been reported to accumulate toxic heavy metals and non-metals such as phosphorous $(\mathrm{P})$, iron $(\mathrm{Fe})$, copper $(\mathrm{Cu})$, potassium $(\mathrm{K})$, magnesium $(\mathrm{Mg})$, boron $(\mathrm{B})$, aluminum $(\mathrm{Al})$, calcium $(\mathrm{Ca})$, lead $(\mathrm{Pb})$, arsenic $(\mathrm{As})$, cadmium $(\mathrm{Cd})$, mercury (Hg) and manganese (Mn) [15]. Some of these metals have been reported to cause neurotoxicity in the brain such as $\mathrm{Al}, \mathrm{Pb}, \mathrm{As}$, and $\mathrm{Cd}$ leading to brain damage [15] and excessive $\mathrm{Ca}^{2+}$ causes excitotoxicity leading to brain damage as well. And also since the country is rich in minerals including heavy metals such as Lead, Mercury, Arsenic, Cobalt and many others; these metals can easily be accessed by the local communities and traditional healers and thus they can use them in preparation of the concoction of the Karuho poison. These heavy metals such as Lead have been reported to cause brain toxicity and hence leads to the observed neurological signs and symptoms in the victims especially if they are exposed for a long time [16] [17] [18]. However, whereas Karuho poison is commonly utilized to harm people and these individuals usually present with neurological and behavioral changes; the effects of Karuho poison 
on the brain have not been scientifically evaluated and the study investigated the sub-acute toxicity of most active Karuho poison (OMGKRP) on the Wistar albino rat brain.

\section{Materials and Methods}

\subsection{Study Design}

It was both cross-sectional study that involved the collection of Karuho poison from the traditional healers and the communities and experimental based design where sub-acute toxicity of the selected Karuho poison on the brain was carried out in Wistar albino rats.

\subsection{Study Setting}

The Karuho poison samples were collected from the different communities of Goma City in DRC and the laboratory experiments were carried out at the department of Pharmacology \& Therapeutics, Makerere University College of Health Sciences (MakCHS) and at the department of Veterinary Pathology Makerere University College of Veterinary Medicine, Animal Resources and Biosecurity (MakCOVAB), Kampala, Uganda.

\subsection{Collection of Karuho Poison Samples}

A total of 12 traditional healers, male and female, that were dealing with Karuho poisoning management for at least 10 years and registered by Health Provincial Inspection Unit of North-Kivu/DRC were visited. Among them, four consented to participate in the study and were recruited as key informants. Key informant interviews using face to face interviews were conducted with them to get information about how and where to get Karuho poison within Goma city. Any Karuho preparation used within Goma city constituted the study unit. However, to ascertain that the provided sample were the genuine one, only Karuho poison preparations from sellers disclosed by key informants was selected and purchased for experimental study.

\subsection{Purchasing, and Handling of Karuho Poison Samples}

Four different Karuho preparations with different codes including OMGKRP, DLNKRP, CHKRP and BHKRP were purchased as any client from different clandestine sellers who happen to be the traditional healers within Goma city. Therefore each of these Karuho poison, were purchased from a well-known traditional healers who prepares it using the same ingredients and therefore to ensure repeatability, such poison can be purchased from the same traditional healer when required. However, the sellers refused to disclose the ingredient of OMGKRP and DLNKRP. Once purchased, samples were sealed in the dry, opaque and closed plastic container before taken to the department of Pharmacology and Therapeutics where the study was conducted. They were kept at temperatures between $2^{\circ} \mathrm{C}-8^{\circ} \mathrm{C}$, under lock and away from research staff. Any han- 
dling was done according to good laboratory practice (GLP) [19].

\subsection{Selection and Handling of Laboratory Experimental Animals}

A total of 48 Swiss albino mice adult male and female aged between 8-12 weeks, weighting $22 \% \pm 20 \%$ and 50 adult Wistar albino rat males and females also aged between $8-12$ weeks and weighting $180 \pm 20 \mathrm{~g}$, bred in COVAB animal houses were randomly selected using the computer (statistical package MINITAB). The purchased and selected mice and rats were housed in animal house at the department of Pharmacology and Therapeutics, MakCHS for 1 week for acclimatization. They were housed under standard environmental conditions, at temperature of $20^{\circ} \mathrm{C}-24^{\circ} \mathrm{C}$; light/dark, hour cycle of $14 / 10$; relative humidity of $65 \%$, given free access to food, water and in mini-cage size of $350 \mathrm{~cm}^{2}$ for rats with freedom of movement [20] [21]. They were fed on commercial rat and mice feed pellet that was purchased from Uganda Grain Miller in Kampala city and with water ad-libitum [22].

\subsection{Selection Criteria of the Animals}

Both males and females animals which were normal as judged by their alertness and $>4$ weeks of age were selected for the study. Sick, pregnant animals and nursing mothers were excluded in this study basing on the ethical guidelines on the Laboratory use of animals in Biomedical research [21].

\section{Experiment Procedures}

\subsection{Preparation of Crude Aqueous Suspension of Each Karuho Poison Sample}

About $10 \mathrm{~g}$ of Karuho poison sample bought from traditional sellers was weighted using analytical balance. Using graduate cylinder or conical flask and glass rod, sample was mixed with distilled water up to 100 milliliters to make a stock suspension of $100 \mathrm{mg} / \mathrm{ml}$ from which suitable dilutions were made in varying doses. Controls received distilled water. The doses were given as $\mathrm{mg} / \mathrm{Kg}$ body weight (bwt) of each Swiss albino mice or Wistar rat.

\subsection{Screening of Karuho Poison Samples for the Most Active Poison}

The 4 collected Karuho poison samples were screened for their toxicity activity at the experimental laboratory at the Pharmacology and Therapeutics Department, MakCHS according to Organization for Economic Cooperation and Development (OECD420, 2001) [21], sight method, using few numbers of mice (n $=2$ for control and each dose level). However, animals were followed up for two months for morbidity and mortality to collect any delayed toxic effect useful in subsequent acute and chronic toxicity studies. The starting dose was $5 \mathrm{mg} / \mathrm{Kg}$ bwt because Karuho poison is used in small doses by unscrupulous individuals to kill their victims during conflicts within Goma city. Then, for each sample, a 
dose ranges from 5, 50, 300 and $2000 \mathrm{mg} / \mathrm{Kg}$ bwt and exceptionally $5000 \mathrm{mg} / \mathrm{Kg}$ as a limit dose were used. The small dose of $5 \mathrm{mg} / \mathrm{Kg}$ was selected basing on 1) that Karuho poison is used in small doses by unscrupulous individual to kill their enemies which the victim cannot detect in food or beverage and 2) the OECD methods used as guideline $\left(\mathrm{OECD}_{420}\right.$ and $\left.\mathrm{OECD}_{407}\right)$, they recommend the use of $5 \mathrm{mg} / \mathrm{Kg}$ body weight of the animal as starting dose (small dose) in acute oral toxicity study and is useful as reference in classifying hazardous substances as very toxic or category 1 ( $\leq 5 \mathrm{mg} / \mathrm{Kg}$ ) (GHS (Rev.7) (2017) [41]. According to OECD420 (2001) method [21], for the acute toxicity study, a single dose is given and if no mortality occurs within 24 hours, animals were observed for 14 days for any delayed toxic effects. Thus, OMGKRP caused evident toxic effects within 14 days at lowest dose level of $5 \mathrm{mg} / \mathrm{Kg}$ bwt though no mortality was observed within that period as compared to the other Karuho poisons. OMGKRP was then selected as the most effective toxic sample and was selected for acute toxicity test in mice and thereafter for sub-acute toxicity effects on the brain of Wistar albino rats.

\subsection{Acute Toxicity Test of OMGKRP in Swiss Albino Mice}

This was done according to OECD420 (2001) method [21]. A total of 36 mice in 6 groups each with 6 animals of both sexes in equal number were used and animal in each group was dosed 5, 50, 300, 2000 and exceptional limit dose of 5000 $\mathrm{mg} / \mathrm{Kg}$ bwt and control group was given distilled water. Starting dose selected from preliminary study was $5 \mathrm{mg} / \mathrm{Kg}$ bwt and all the six mice in each group received single dose level by oral route using intragastric tube according to acute toxicity fixed dose procedure OECD 420 (2001) [21]. The test dose and distilled water used as control were administered in constant volume of $2 \mathrm{mg} / 100 \mathrm{~g}$ bwt and were blinded (to lab assistants) using codification system. Mice were starved; food but not water for 3 - 4 hours prior to dosing [21], to prevent irregularity in absorption of Karuho poisons [23]. Following fasting period, mice were weighed and the doses of Karuho poison and controls were administered. After oral administration of the desired dose, each mouse was returned to the cage in its respective group. Food was withheld for further $1-2$ hours after dose of Karuho poison administration and then after which, mice were allowed free access to food and water [21]. Mortality after 24 hours of dosing and behavioral changes was noted for all the animals in all the groups.

\subsection{Determination of Sub-Acute Toxic Effect on Wistar Albino Rat Brain Tissue}

Three dose levels including 1, 5 and $20 \mathrm{mg} / \mathrm{Kg}$ bwt were selected from acute toxicity study and were administered daily to Wistar albino rats for 28-days according to 407 methods [24]. Unexceptional dose of $5000 \mathrm{mg} / \mathrm{Kg}$ was used as fourth dose as a way to compare its toxic effects to that of lowest dose that is commonly used by unscrupulous individuals. Thus, rats were randomly divided 
into five groups with each having 10 animals of both sexes in equal number for each group. They were starved overnight prior to administration of OMGKRP doses. The tested substance and distilled water were orally administered daily by intragastric tube in graduated dose levels once daily for a period of 28 days [24]. Food was withheld for 3 - 4 hours after administration of Karuho poison and for the control group. Thereafter animal had free access to food and water.

\subsection{Cage Side Observation}

During the period of administration, the rats were closely observed daily, for signs of toxicity for up to 28 days. Thereafter rats were kept for 14 days for any delayed evident toxic effect according to OECD method [24]. At the end of the test, surviving rats were weighed and then sacrificed using standard methods (using ethyl-ether as anesthetic).

\subsection{Histopathological Analysis of the Brain}

This was performed at the Department of Pathology at COVAB, Makerere University. The brain of sacrificed Wistar rats were transferred to $4 \%$ formalin solution for fixation and later on processed for histopathological studies following the standard procedure described by Raghuramulu et al. (1983) [25]. The microtome sections were made, processed and stained with haematoxylin and eo$\sin$. The sections of the brain were mounted on the slide and viewed using binocular research Nikon Eclipse Ci-S microscope (Japan) under different magnifications. Changes, if any in the brain Cyto-architecture were noted. Also, toxic effects of OMGKRP were deducted from signs/symptoms presented by treated Wistar rats [26].

\subsection{Data Analysis}

Data on signs/symptoms (qualitative data) presented by treated rats involved organization, categorization, a search for patterns, and their synthesis or summarizing as number of animals affected, time course of toxic effect and displayed in table. Also, changes in brain cytoarchitecture were revealed by photomicrography analysis using comparison between control brain tissue (normal brain tissue) and treated rats brain tissues.

Quantitative data was analyzed using XLSTAT version 2017.5 statistical package. Repeated measures two-way ANOVA was used to compare means within and between groups. Mauchly's sphericity test was used to validate a repeated measures analysis of variance (ANOVA) and Greenhouse-Geisser correction (F-test) for violation of sphericity or to correct variance value for any effect in the groups was used. A probability value of $p<0.05$ was considered statistically significant.

\subsection{Ethical Consideration}

Ethical approval to conduct the study was sought from the Department of 
Pharmacology and Therapeutics, MakCHS, School of Biomedical Sciences Higher degrees Research and Ethics Committee (IRB) with approval number SBS 346, Research and Ethics Committee of ULPGL. And the study was carried out according to the international standard guidelines on use of laboratory animals in biomedical research [22] [21].

\section{Results}

1) Sample collection and raw materials used in Karuho poison preparation

A total of 12 traditional healers that were dealing with Karuho poisoning management for at least 10 years and registered by Health Provincial Inspection Unit of North-Kivu/DRC were visited. Among them, four consented to participate in the study and a total of 4 Karuho samples coded as OMGKRP, DLNKRP, CHKRP and BHKRP were collected from each of the 4 traditional healers. However, $50 \%(n=2)$ of the sellers refused to disclose the raw materials for OMGKRP and DLNKRP Karuho poison. And yet for the other 50\% $(\mathrm{n}=2)$, various raw materials were mentioned by the traditional healers that were interviewed during the sample collection and they included use of plant extracts, glass, heavy metals/minerals, human placenta, venoms from the skin of the toads/frogs, chameleon, blue Agama lizard, crocodile bile and old car battery acid (Figure 1).

2) Screening of Karuho poison samples for acute toxicity to identify the most active one to be used in sub-acute toxicity in Swiss albino mice

All the 4 Karuho poison samples collected including OMGKRP, DLNKRP, CHKRP and BHKRP were screened for acute toxicity in Swiss albino mice and none of them was able to cause death within 24 hours. However, they were followed up for 60 days for observation of any clinical signs/symptoms such as shortness of breath, piloerection, depression, weight changes and loss of appetite for food and water as well as their duration of onset were noted for each poison. The findings showed that OMGKRP Karuho poison was the most active of all the 4 poisons tested with the shortest duration of onset of the clinical signs/symptoms as early as 7 days of observation for shortness of breath and depression (Table 1). Therefore, OMGKRP Karuho poison was selected for the sub-acute toxicity study to determine its effects on the brain of the Wistar albino rats.

3) Sub-acute toxicity signs and symptoms of a single dose of varying doses of OMGKRP in Wistar albino rats

The effects of a single dose of the varying doses of OMGKRP Karuho poison in Wistar albino rats on the signs/symptoms and weight were noted and the findings showed that the onset of depression, piloerection and shortness of breath was observed at the $7^{\text {th }}$ day at doses of 5 and $20 \mathrm{mg} / \mathrm{Kg}$ bwt of the poison (Table 2). However, 20\% $(\mathrm{n}=2 / 10)$ mortality was observed at a dose of $5 \mathrm{mg} / \mathrm{Kg}$ bwt on the $18^{\text {th }}$ day of follow up and observation (Table 2). On the body weight 


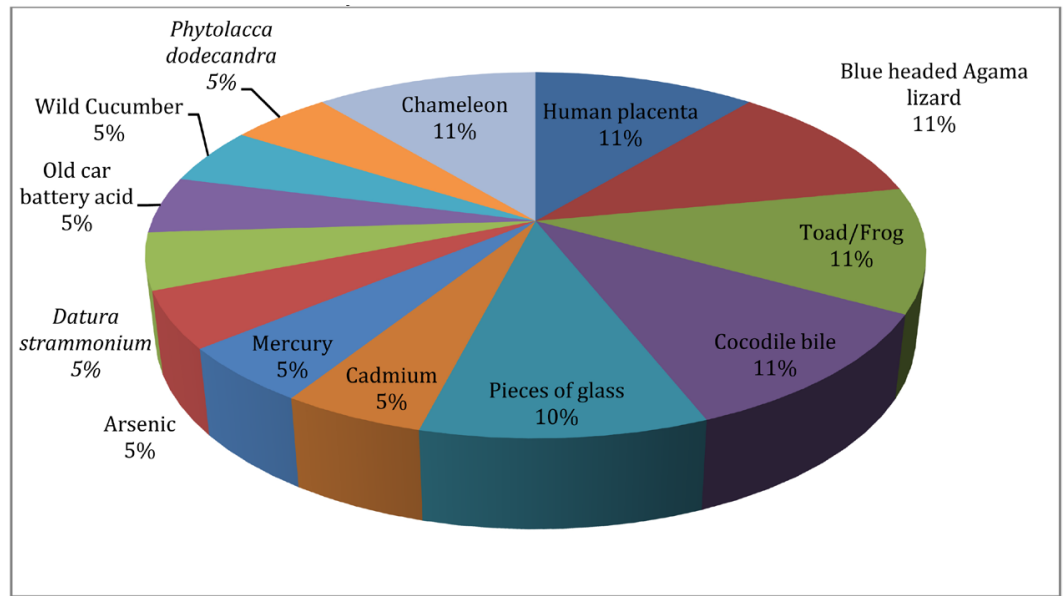

Figure 1. Raw materials used in Karuho poison preparation presented in percentage of their mentions by interviewed traditional healers

Table 1. Screening preliminary result of acute toxicity test for the four collected Karuho poison samples in Swiss albino mice (Based on Teo and al, 2002) [35].

\begin{tabular}{ccccc}
\hline $\begin{array}{c}\text { Signs/symptoms observed for } \\
\text { different Karuho poisons at a lower } \\
\text { dose of 5mg/kg bwt }\end{array}$ & $\begin{array}{c}\text { Duration of onset of toxic effect for the different type of } \\
\text { Karuho poison (Days) }\end{array}$ \\
\cline { 2 - 5 } & OMGKRP & DLNKRP & CHKRP & BHKRP \\
\hline Death within 24 hours (1 day) & 0 & 0 & 0 & 0 \\
Decrease in body weight (g) & 14 (Severe) & 21 (Severe) & 0 & 14 (Moderate) \\
Shortness of breath & 7 (Severe) & 26 (Severe) & 0 & 46 (Moderate) \\
Decrease in food and water intake & 14 (Severe) & 21 (Severe) & 0 & 14 (Moderate) \\
Piloerection & 10 (Severe) & 26 (Severe) & 0 & 46 (Moderate) \\
Depression & 7 (Severe) & 7 (Moderate) & 0 & 7 (Moderate) \\
\hline
\end{tabular}

Table 2. Duration of onset of signs and symptoms (depression, piloerection and shortness of breath) and death following a single dose of varying doses of OMGKRP in treated groups of Wistar albino rats (Days).

\begin{tabular}{cccccc}
\hline $\begin{array}{c}\text { Dose } \\
(\mathrm{mg} / \mathrm{kg} \\
\text { bwt })\end{array}$ & $\begin{array}{c}\text { No. } \\
\text { animals } \\
(\mathrm{n})\end{array}$ & $\begin{array}{c}\text { Duration of onset of signs and } \\
\text { symptoms (Depression, } \\
\text { piloerection and shortness of } \\
\text { breath) }\end{array}$ & $\begin{array}{c}\text { Duration of } \\
\text { onset death } \\
\text { (Days) }\end{array}$ & $\begin{array}{c}\%(\mathrm{n}) \\
\text { morbidity }\end{array}$ & $\begin{array}{c}\%(\mathrm{n}) \\
\text { mortality }\end{array}$ \\
\hline Control & 10 & 0 & 0 & 0 & 0 \\
1.0 & 10 & 10 & 27 & $100.0(\mathrm{n}=10)$ & $10.0(\mathrm{n}=1)$ \\
$\mathbf{5 . 0}$ & 10 & 7 & 18 & $100.0(\mathrm{n}=10)$ & $20.0(\mathrm{n}=2)$ \\
$\mathbf{2 0 . 0}$ & 10 & 7 & 27 & $100.0(\mathrm{n}=10)$ & $10.0(\mathrm{n}=1)$ \\
$\mathbf{5 0 0 0 . 0}$ & 10 & 10 & 0 & $100.0(\mathrm{n}=10)$ & $0.0(\mathrm{n}=0)$ \\
\hline
\end{tabular}

changes, there was a gradual decline in body weight for all the doses including 1.0, 5.0, 20.0 and $5000.0 \mathrm{mg} / \mathrm{Kg}$ bwt and a significant decline was observed at a dose of 5.0 and $20.0 \mathrm{mg} / \mathrm{Kg}$ bwt for both male and females, males and females respectively as compared to the control group (Figures $2(\mathrm{a})-(\mathrm{c})$ ). 


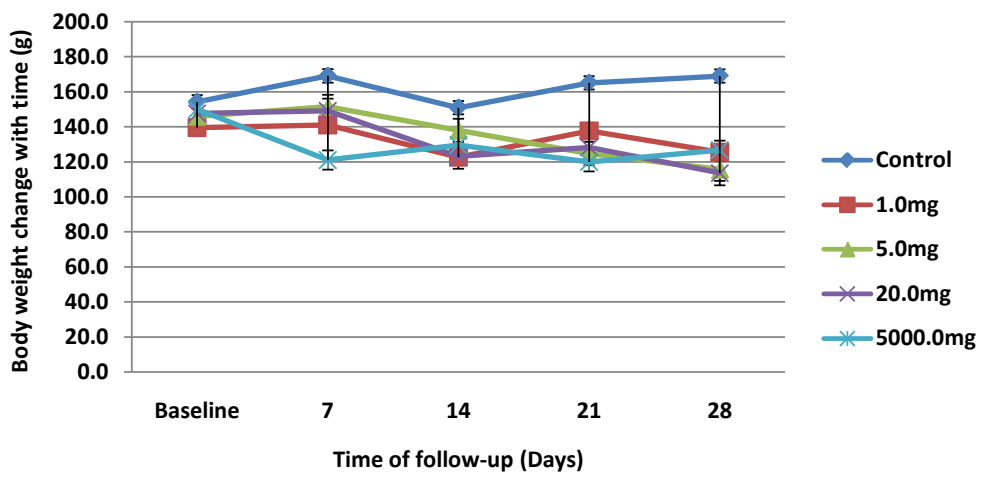

(a)

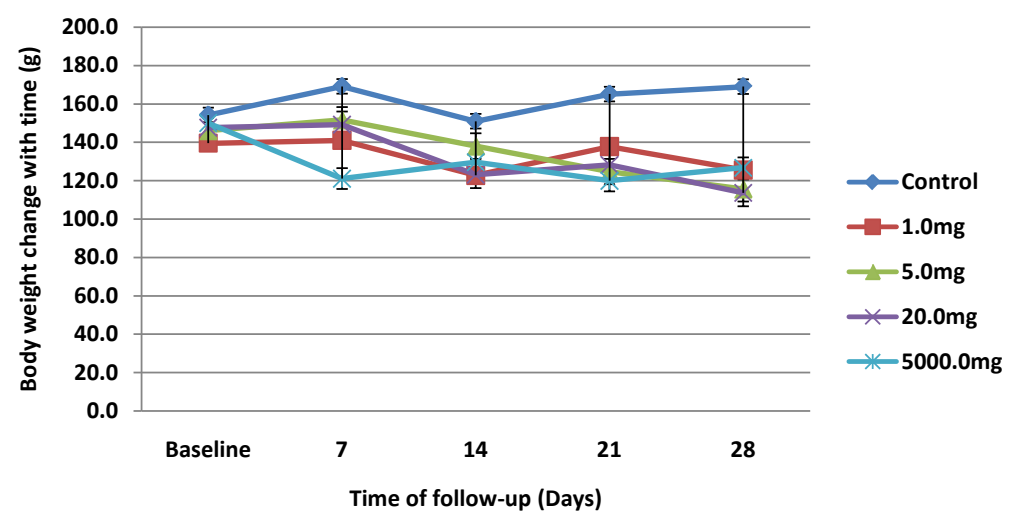

(b)

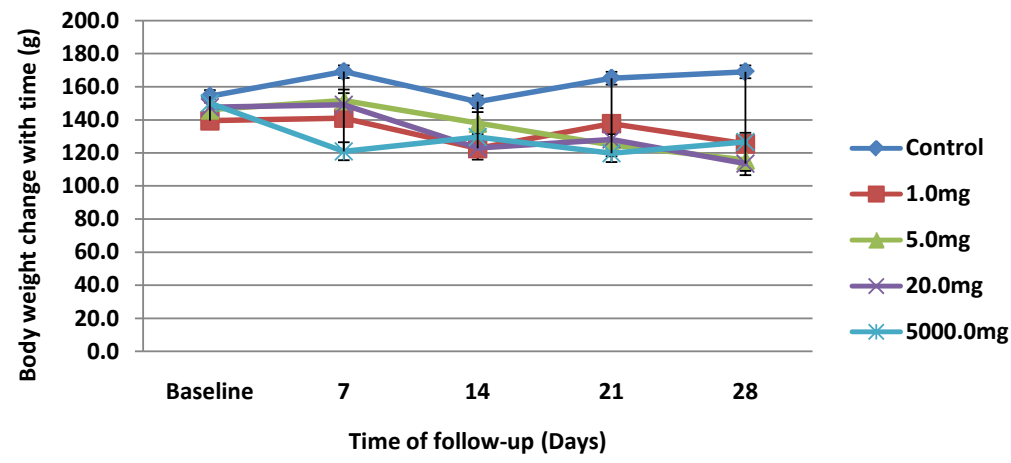

(c)

Figure 2. Body weight change with time following repeated dosing with varying doses of OMGKRP in Wistar albino rats for 28 days. (a) Body weight change with time following repeated dosing with varying doses of OMGKRP in both males and female Wistar albino rats for 28 days $(\mathrm{n}=10)$. Greenhouse-Geisser correction (F-test) for violation of sphericity was $\mathrm{F}(4.36)=0.877, p=0.0001$ which was statistically significant between and within group treatments for both males and females Wistar albino rats; (b) Body weight change with time following repeated dosing with varying doses of OMGKRP in males Wistar albino rats for 28 days $(\mathrm{n}=5)$. Greenhouse-Geisser correction (F-test) for violation of sphericity was $\mathrm{F}(4.15)=0.640, p=0.000$ which was statistically significant between and within group treatments for male Wistar albino rats; (c) Body weight change with time following repeated dosing with varying doses of OMGKRP in females Wistar albino rats for 28 days $(\mathrm{n}=5)$. Greenhouse-Geisser correction (F-test) for violation of sphericity was $\mathrm{F}(4.16)=0.534, p=0.000$ which was statistically significant between and within group treatments for female Wistar albino rats. 


\section{4) Histopathological analysis of the effect of OMGKRP Karuho poison on} the brain of Wistar albino rats

The effect of OMGKRP Karuho poison on the brain of Wistar albino rats at the sub-acute dose of $1.0 \mathrm{mg} / \mathrm{Kg}$ bwt was determined and the findings showed that there was moderate to diffuse congestion and mononuclear inflammatory cells infiltration (plasma cells, lymphocytes and macrophage) in the meninges and cerebellum region (Figure 3). There was on significant morphological changes observed in the architecture of other parts of brain tissues including the cerebral cortex in the brain.

\section{Discussion}

Karuho poisoning is a common public health challenge in Eastern Democratic Republic of Congo (DRC) especially in the Goma city in the North Kivu province and in the neighboring country Rwanda. It is used as a weapon to harm others or as revenge during conflicts among the different communities. The finding from the study showed that there are different types of Karuho poisons depending on the raw materials used in the concoction (Figure 1) and the signs/symptoms observed in the individuals poisoned by particular Karuho poisonmay present as acute or chronic depending on the dose and the type of poison used (Table 1). And in most cases, the signs/symptoms presented resembles those observed in others diseases including tuberculosis, HIV/AIDS, typhoid fever, cancer, malaria and many others. These signs/symptoms usually are confused with Karuho poisoning as reported by the communities and traditional healers in the Goma city as well as causing a mystery in the medical world since there is no scientific evidence and therefore this causes a delay in seeking medical treatment and hence causing high mortality morbidity and disability among the affected individuals in the communities.

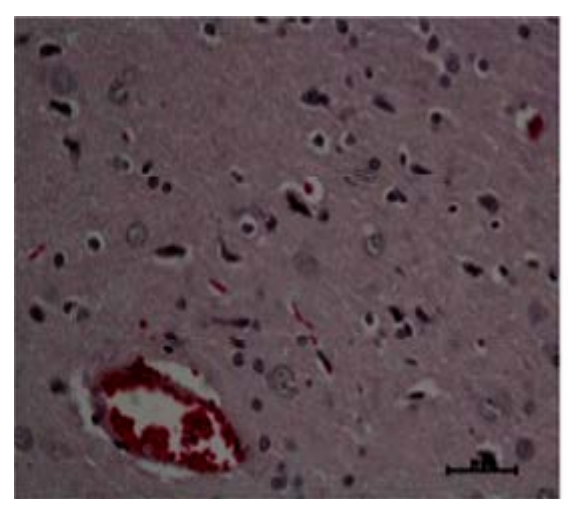

(a)

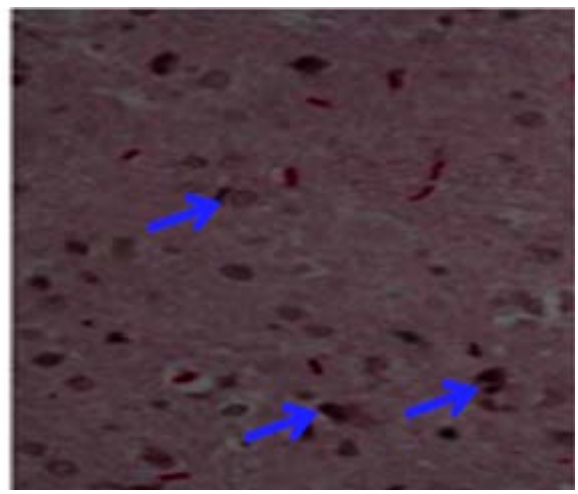

(b)

Figure 3. Photomicrographs of Swiss albino rat brain tissue following different sub-acute doses of OMGKRP. Arrow key: (a) Normal brain tissue and (b) sub-acute dose of $1 \mathrm{mg} / \mathrm{kg}$ bwt of OMGKRP poison showing Moderate diffuse congestion and mononuclear inflammatory cells infiltration (plasma cells, lymphocytes and macrophages) into the meninges at cerebellar region but with no morphological changes 
A total of 4 Karuho poisons were collected including OMGKRP, DLNKRP, CHKRP and BHKRP. However, in the 50\% $(\mathrm{n}=2 / 4)$, the OMGKRP and DLNKRP Karuho poisons that were collected; their raw materials used in their preparations were a secret and the respondents refused to reveal their components. And one of them, OMGKRP was the most active poison. While for CHKRP and BHKRP Karuho poison, whose raw materials were mentioned, the study findings showed that there are different raw materials used in the preparation of various types of Karuho poison in the different communities and traditional healers in Goma city, with different poisoning potential in the victims. Among the raw materials used in the 50\% $(\mathrm{n}=2 / 4)$ Karuho poisons that were collected included toxic medicinal plants such as Phytolacca dodecandra (5\%), Wild cucumber (5\%), Datura strammonium (5\%); heavy metals included Arsenic (5\%), Mercury (5\%), Cadmium (5\%); pieces of glasses (10\%); animal part such as human placenta (11\%), Blue headed Agama lizard (11\%), chameleon (11\%) and venoms from the skin of the toads/frogs (11\%), crocodile bile (11\%) and old car battery acid (5\%) (Figure 1). The findings were similar to what has been reported by the communities and literature; that Karuho poison is a common problem in the region and it is usually made from the local natural products including venoms derived from chameleon and toad/frog skin, blue headed Agama lizard, human placenta or some rare plant extracts such as Datura stramonium and some minerals like arsenic, mercury and cadmium and many others [1] [2] [5]. Also previous studies have been reported that there are various medicinal plants that are toxic and hence can be used in Karuho poison preparation and they include Cymbopogon species, Artemisia species, Cynanchum argel delile, Equisetum, and Vitex agnus-castus and many of these have been reported to accumulate toxic heavy metals and non-metals such as phosphorous (P), iron $(\mathrm{Fe})$, copper $(\mathrm{Cu})$, potassium $(\mathrm{K})$, magnesium $(\mathrm{Mg})$, boron $(\mathrm{B})$, aluminum $(\mathrm{Al})$, calcium $(\mathrm{Ca})$, lead $(\mathrm{Pb})$, arsenic $(\mathrm{As})$, cadmium $(\mathrm{Cd})$, mercury $(\mathrm{Hg})$ and manganese (Mn) [15], that are toxic to humans and animals. Therefore Karuho poison is common, real and a public health challenge in the region and they are prepared from the available local natural products.

1) Screening of Karuho poison samples for acute toxicity to identify the most active one to be used in sub-acute toxicityin Swiss albino mice

The 4 Karuho poisons collected including OMGKRP, DLNKRP, CHKRP and BHKRP were screened for acute toxicity in Swiss albino mice. There was no death recorded within 24 hours of dosing the animals for all the poisons collected. For OMGKRP, DLNKRP and BHKRP when followed up for 60 days, the findings showed a decrease in body weight, shortness of breath, piloerection, depression and reduction in water and food intake and the duration of onset of the signs/symptoms varied with OMGKRP being the most active (Table 1). While CHKRP Karuho poison was the least active and there was no visible signs/symptoms observed during the period of follow up (Table 1). Therefore, OMGKRP Karuho poison was selected for the sub-acute toxicity study to deter- 
mine its effects on the brain of the Wistar albino rats. The findings from the screening of the different types of Karuho poison on the signs/symptoms are similar to what has been reported in previous studies. According to Simisi (2000) [7] and Uwizeye (2004) [6], poisoned individuals by the different type of Karuho poison, are usually reported to present with either acute signs including nausea and vomiting with atrocious pain of epigastrium, agitation, profuse sweat, and shortness of breath, loss of consciousness, hematemesis, convulsion and death in few hours while the chronic ones include emaciation, cough, chest discomfort, fever, effort dyspnea, nausea and change in hair color. And these signs/symptoms are commonly confused with those of tuberculosis (TB), typhoid fever (TF), cancer, HIV/AIDS and many other chronic conditions/diseases hence causing a delay in seeking medical attention since such affected individuals think that they have been poisoned by Karuho poison.

2) Sub-acute toxicity signs and symptoms of a single dose of varying doses of OMGKRP in Wistar albino rats

The effect of a single dose of the varying doses of the selected most active Karuho poison OMGKRP in Wistar albino rats on the observed signs/ symptoms and their onset including depression, piloerection, shortness of breath and body weight changes as well as death were noted during the 28 days of follow up. The findings showed that the onset of depression, piloerection and shortness of breath was observed at the $7^{\text {th }}$ day at doses of 5 and $20 \mathrm{mg} / \mathrm{Kg}$ bwt of the poison respectively (Table 2). However, 20\% $(\mathrm{n}=2 / 10)$ mortality was observed at a dose of $5 \mathrm{mg} / \mathrm{Kg}$ bwt on the $18^{\text {th }}$ day of follow up and observation (Table 2). On the body weight changes, there was a gradual decline in body weight for all the doses including 1.0, 5.0, 20.0 and $5000.0 \mathrm{mg} / \mathrm{Kg}$ bwt and a significant decline was observed at a dose of 5.0 and $20.0 \mathrm{mg} / \mathrm{Kg}$ bwt for both male and females, males and females respectively as compared to the control group (Figures 2(a)-(c)). The findings agree with what has been reported in previous studies elsewhere that have reported that individuals who are poisoned by Karuho chronically present with loss of weight, shortness of breath, cough, nausea and vomiting and change in hair color and these signs/symptoms are commonly confused with those of tuberculosis (TB), typhoid fever (TF), cancer, HIV/AIDS and many others hence leading to a delay in seeking for medical treatment for those conditions [6] [7].

Actually, it has been reported by Simisi (2000) [7] and Uwizeye (2004) [6] that depression, weakness and fatigue are among signs and symptoms presented by patient victims of Karuho poisoning. According to Hasler (2010) [27], there are two hypotheses regarding the pathophysiological mechanism of depression. The first hypothesis stipulates that depression is related to a deficiency in the amount or function of cortical and limbic serotonin, norepinephrine and dopamine. The second hypothesis stipulates that changes in trophic factors, especially brain-derived neurotrophic factor (BDNF) and hormones play a major role in the development of major depression. This suggests that Karuho poison may cause deficiency of 
serotonin, norepinephrine, dopamine or BDNF. Several animal and human studies have indicated that stress and pain are associated with a drop in BDNF levels and that this loss of neurotrophic support contributes to atrophic structural changes in the hippocampus and perhaps other areas such as the medial frontal cortex and anterior cingulated [27]. The hippocampus is known to be important in hypothalamic-pituitary-adrenal axis. Likewise, the anterior cingulate plays a role in the integration of emotional stimuli and attention functions, whereas the medial orbital frontal cortex is also thought to play a role in memory, learning, and emotion [27]. Indeed, in the present study, all treated Wistar rats were associated with changes in behavior including depression, piloerection, loss of appetite, loss in body weight and reduction of movement that may be related to stress and pain. Piloerection is a sympathetic reflex caused by conditions including stress, pain, fever etc. It has been reported by Kikuchi-Utsumi et al. (2013) [28] that $\alpha$-1A-adrenergic receptor activation and prostaglandins participate in the regulation of piloerection mechanism. The behavior changes in treated group were not observed in control group.

3) Histopathological analysis of the effect of OMGKRP Karuho poison on the brain of Wistar albino rats

The effect of OMGKRP Karuho poison on the brain of Wistar albino rats at the sub-acute dose of $1.0 \mathrm{mg} / \mathrm{Kg}$ bwt was determined and the findings showed that there was moderate to diffuse congestion and mononuclear inflammatory cells infiltration (plasma cells, lymphocytes and macrophage) in the meninges and cerebellum region (Figure 3 ). There was on significant morphological changes observed in the architecture of other parts of brain tissues including the cerebral cortex in the brain. The findings concur with the previous similar studies done elsewhere. It has been reported that reduction of movement may be caused by cerebellum tissue damage [29]. Cerebellum dysfunction occurs in association with exposure to a wide variety of toxins, including drugs, solvents, and heavy metals [39]. These toxins may adversely affect the cerebellum directly or as part of a more generalized encephalopathy. Actually, in the present study, Wistar rats were treated by sub-acute dose of OMGKRP crude aqueous suspension, a mixture of volatile solvent with minerals (arsenic, cadmium and mercury), secret plants, reptile and toad/frog. It has been reported that exposure to a wide variety of volatile solvents may cause ataxia along with other neurologic problems, including cognitive impairment, and pyramidal signs [30] [31] [32] [33]. As with drug toxicity, these deficits are usually reversible unlessexposure has been heavy and prolonged. These volatile chemicals are ubiquitous in Goma city and are found in many products, such as adhesives, solvents, aerosols, and fire extinguishers that may be used in Karuho poison preparation. Also, several studies have revealed that poisoning with heavy metals such as mercury, manganese, bismuth, thallium, and lead can result in neurologic syndromes, including prominent ataxia [31] [32]. According to De Furia \& Shea (2007) [34], mercury can migrate to the brain and inhibit some of the crucial functions of the 
blood brain barrier. Furthermore, it has been reported that, some skin of toad/frog (Atelopus) secrete tetrodotoxin, a neurotoxin that block $\mathrm{Na}^{+}$channels [36]. Indeed, neurotoxins affect the nervous system by diverse mechanisms through which they function in the inhibition of neuron cellular processes [37]. These inhibited processes include membrane depolarization mechanisms and inter-neuron communication therefore inhibiting the ability for neurons to perform their expected intracellular functions, or pass a signal to a neighboring cell [37]. However, histopathological analysis revealed diffuse congestion and mononuclear inflammatory cells infiltration (plasma cells, lymphocytes and macrophage) into the meninges at cerebellar region that may suggest that OMGKRP induced aseptic meningitis of that region. According to Jolles \& all (2000) [38], there are 2 major proposed mechanisms for xenobiotic inducing meningitis. The first involves direct irritation of the meninges by intrathecal administration of the drug, and the second involves immunological hypersensitivity to the drug, most likely type III and type IV hypersensitivity. The fact that meninges at the cerebellar region were infiltrated by mononuclear inflammatory cells suggesting that OMGKRP was not safe. It may also contain solvent or heavy metals or neurotoxins that induce inflammation of cerebellar meninges by unclear mechanism following sub-acute doses. The findings from the previous studies also indicate that various chemical poisons of natural origin such as heavy metals and those from medicinal plants can cause serious damage to the cerebellum [39], that may be present in the Karuho poison. Though, however, some of these medicinal plants have been reported to have neuroprotective effects on the brain [40], and thus reversing the neurotoxicity caused by the chemical substances used in preparation of the different types of Karuho poison. Karuho poison is a common problem in Eastern DRC in the city of Goma and prolonged small doses of the OMGKRP causes behavioral changes including depression, motor effects and loss of appetite in affected individuals as observed in the laboratory animals in this study.

\section{Conclusion}

The study revealed that Wistar albino rats treated by sub-acute doses OMGKRP, one of different Karuho poison used by unscrupulous individuals to cause homicide in Goma city, were associated with brain damages especially with inflammation of the meninges at cerebellar region of treated Wistar rat. The damages caused by the OMGKRP poison in the brain after prolonged exposure to the Wistar albino rats caused signs and symptoms including depression, pilo-erection, ataxia and reduction in movement, shortness of breath and death that were similar to what is observed in victims of Karuho poison in Goma City, DRC.

\section{Acknowledgements}

I am grateful to all staff members of the Department of Pharmacology \& Thera- 
peutics Makerere University College of Health Science, All Ethical committee of Makerere University, ULPGL Goma and to the Directorate of Health Services in Goma city/DRC. I am also very grateful to my study participants and my research assistants.

\section{Conflict of Interest}

The authors declare no conflicts of interest.

\section{References}

[1] Ianinrwanda. Witchcraft and Poison in Rwanda: Ian in Rwanda, 2012. http://ianinrwanda.blogspot.ug/2012/06/witchcraft-and-poison-in-rwanda.html

[2] Nsapu, E. (2014) Traditional Healer in DRC Treats Suspected Poisoning Victims Regardless of Tribe. Global Press Journal, Africa, Democratic Republic of Congo. https://globalpressjournal.com/africa/democratic-republic-of-congo/traditional-hea ler-in-drc-treats-suspected-poisoning-victims-regardless-of-tribe/

[3] Kaboru, B. and Namegabe, E. (2014) Geographical, Health Systems and Ociocultural Patterns of TB/HIV Co-Infected Patients Health Seeking Behavior in a Conflict Affected Setting: The Case of Eastern Democratic Republic of Congo. Journal of Community Medicine \& Health Education.

[4] UNODC (2013) Global Study on Homicide 2013: Trends, Contexts, and Data. United Nations Office on Drugs and Crime, Vienna. United Nations Publication, 39-58.

https://www.unodc.org/documents/gsh/pdfs/2014_GLOBAL_HOMICIDE_BOOK_ web.pdf

[5] IRIN (2009) Toxic Toad Scam Killing Patients: Health News, GOMA. irinnews.org. http://www.irinnews.org/report/84354/drc-toxic-toad-scam-killing-patients

[6] Uwizeye, O. (2004) Ethnobotanical Survey of Plants Used against Poisons "Karuho" in Goma Health District. Université Libre des Pays des Grands Lacs (ULPGL). (Unpublished).

[7] Simisi, K. (2000) Contribution à l'étude des plantes médicinales utilisées contre l'empoisonnement dans la collectivité de Bwisha, territoire de Rutsuru. Faculty of Medicine, University of Goma/DRC.

http://www.congo-autrement.com/page/sante/le-saviez-vous-le-charbon-makala-un -anti-poison-ultra-puissant.html

[8] WHO (2009) WHO Monographs on Selected Medicinal Plants. WHO Monographs on Selected Medicinal Plants, 4, 1-444.

http://www.who.int/medicines/areas/traditional/SelectMonoVol4.pdf

[9] Balkrishna, A. and Misra, L.N. (2017) Ayurvedic Plants in Brain Disorders: The Herbal Hope. Journal of Traditional Medicine \& Clinical Naturopathy, 6, 1-9.

https://www.omicsonline.org/open-access/ayurvedic-plants-in-brain-disorders-theherbal-hope.pdf

[10] Lundstrom, K., Thanh, H.P. and Dinh, L.D. (2017) Interaction of Plant Extracts with Central Nervous System Receptors: Review. Medicines, 4, 12. https://doi.org/10.3390/medicines4010012

[11] Taïwe, G.S. and Kuete, V. (2014) 14-Neurotoxicity and Neuroprotective Effects of African Medicinal Plants: Toxicological Survey of African Medicinal Plants. Elsevier, 423-444. https://doi.org/10.1016/B978-0-12-800018-2.00014-5 
[12] Uddin, R., Kim, H.H., Lee, J. and Park, S.U. (2013) Neuroprotective Effects of Medicinal Plants. EXCLI Journal, 12, 541-545. http://www.excli.de/vol12/Lee_Park_14062013_proof.pdf

[13] Chan, T., Chan, L.Y., Tam, L.S. and Critchley, J. (1995) Neurotoxicity Following the Ingestion of a Chinese Medicinal Plant, Alocasia macrorrhiza. Human \& Experimental Toxicology, 14, 727-728. https://doi.org/10.1177/096032719501400905

[14] Devi, M.R., Bawari, M. and Paul, S.B. (2013) Neurotoxic Effect of Albizia myriophylla benth: A Medicinal Plant in Male Mice. International Journal of Pharmacy and Pharmaceutical Sciences, 5, 243-248. http://www.ijppsjournal.com/Vol5Issue3/6776.pdf

[15] Brima, E.I. (2017) Toxic Elements in Different Medicinal Plants and the Impact on Human Health. International Journal of Environmental Research and Public Health, 14, 1209. https://doi.org/10.3390/ijerph14101209

[16] Tchounwou, P.B., Yedjou, C.G., Patlolla, A.K. and Sutton, D.J. (2012) Heavy Metals Toxicity and the Environment. EXS, 101, 133-164.

https://www.ncbi.nlm.nih.gov/pmc/articles/PMC4144270/pdf/nihms414261.pdf https://doi.org/10.1007/978-3-7643-8340-4_6

[17] Jan, A.T., Azam, M., Siddiqui, K., Ali, A., Choi, I. and Haq, Q.M.R. (2015) Heavy Metals and Human Health Review: Mechanistic Insight into Toxicity and Counter Defense System of Antioxidants. International Journal of Molecular Science, 16, 29592-29630. https://doi.org/10.3390/ijms161226183

[18] Matta, G. and Gjyli, L. (2016) Mercury, Lead and Arsenic: Impact on Environment and Human Health. Journal of Chemical and Pharmaceutical Sciences, 9, 718-725. https://www.researchgate.net/publication/302393372_Mercury_lead_and_arsenic_I mpact_on_environment_and_human_health

[19] NRC (2011) Prudent Practices in the Laboratory: Handling and Management of Chemical Hazards. Updated Version, National Research Council (NRC) of the National Academies, National Academies Press, Washington DC. https://www.ncbi.nlm.nih.gov/books/NBK55878/pdf/Bookshelf_NBK55878.pdf

[20] Ghosh, M. (2007) Fundamentals of Experimental Pharmacology. Indian Journal of Pharmacology, 39, 216.

[21] OECD (2001) Acute Oral Toxicity Fixed Dose Procedure. https://ntp.niehs.nih.gov/iccvam/suppdocs/feddocs/oecd/oecd_gl420.pdf

[22] NIH (2011) Guide for the Care and Use of Laboratory Animals. 8th Edition, National Research Council of the National Academies Press, Washington DC.

http://grants.nih.gov/grants/olaw/Guide-for-the-care-and-use-of-laboratory-animal s.pdf

[23] Brunton, L., Knollman, B. and Hilal-Dandan, R. (2017) Drug Toxicity and Poisoning. Goodman and Gilman's the Pharmacological Basis of Therapeutics. 13th Edition, McGraw-Hill Medical, New York, Chapter 4, 131-155.

[24] OECD (2008) Repeated Dose 28 Day Oral Toxicity Study in Rodents. http://www.oecd.org/chemicalsafety/testing/37477972.pdf https://www.keepeek.com//Digital-Asset-Management/oecd/environment/test-no-4 07-repeated-dose-28-day-oral-toxicity-study-in-rodents_9789264070684-en\#page1

[25] Raghuramulu, N., Madhavan, N.K. and Kalyan Sundaram, S. (1983) A Manual of Laboratory Techniques. National Institution of Nutrition, Hyderabad, 205-206.

[26] Bhardwaj, S. (2014) Elimination of Young Erythrocytes from Blood Circulation and 
Altered Erythropoietic Patterns during Paraquat Induced Anemic Phase in Mice. PLOS ONE, 9, e99364.

[27] Hasler, G. (2010) Pathophysiology of Depression: Do We Have Any Solid Evidence of Interest to Clinicians? World Psychiatry, 9, 155-161. https://www.ncbi.nlm.nih.gov/pmc/articles/PMC2950973/pdf/wpa030155.pdf

[28] Kikuchi-Utsumi, K., Ishizaka, M., Matsumura, N. and Nakaki, T. (2013) Alpha(1A)-Adrenergic Control of Piloerection and Palpebral Fissure Width in Rats. Autonomic Neuroscience, 179, 148-150. https://doi.org/10.1016/j.autneu.2013.04.011

[29] Gilman, S. (1992) Cerebellum and Motor Dysfunction. In: Asbury, A.K., McKhann, G.M. and McDonald, W.I., Eds., Diseases of the Nervous System, Clinical Neurobiology, 2nd Edition, WB Saunders, Philadelphia, Chapter 23.

[30] Fornazzari, L., Wilkinson, D.A., Kapur, B.M. and Carlson, P.L. (1983) Cerebellar, Cortical and Functional Impairment in Toluene Abusers. Acta Neurologica Scandinavica, 67, 319-329. https://doi.org/10.1111/j.1600-0404.1983.tb03149.x

[31] Goetz, C. and Cohen, M. (1992) Neurotoxic Agents. In: Joynt, R.J., Ed., Clinical Neurology, JB Lippincott, Philadelphia, Vol. 2, Chapter 20.

[32] Johnson, L., Hubble, J. and Koller, W. (1993) Effect of Medications and Toxins on Cerebellar Function. In: Lechtenberg, R., Ed., Handbook of Cerebellar Diseases, Marcel Dekker, New York, 537-546.

[33] Lotin, Y. (1989) Chronic Neurological Toxicity Associated with Exposure to Volatile Substances. Human Toxicology, 8, 293-300. https://doi.org/10.1177/096032718900800407

[34] DeFuria, J. and Shea, T.B. (2007) Arsenic Inhibits Neurofilament Transport and Induces Perikaryal Accumulation of Phosphorylated: Role of JNK and GSK-3 $\beta$. Brain Research, 1181, 74-82. https://doi.org/10.1016/j.brainres.2007.04.019

[35] Teo, S., Stirling, D., Thomas, S., Hoberman, A., Kiorpes, A. and Khetani, V. (2002) A 90-Day Oral Gavage Toxicity Study of D-Methylphenidate and D, L-Methylphenidate in Sprague Dawley Rats. Toxicology, 179, 183-196. https://doi.org/10.1016/S0300-483X(02)00338-4

[36] Bonfoco, E. (1993) Apoptosis and Necrosis: Two Distinct Events Induced, Respectively, by Mild and Intense Insults with N-Methyl-D-Aspartate or Nitric Oxide/Superoxide in Cortical Cell Cultures. Proceedings of the National Academy of Sciences, 92, 7162-7166.

[37] William, A. and Kenneth, M. (2008) Local Anesthetics. In: Laurence, L., Ac, B. and Ck, B., Eds., The Pharmacological Basis of Therapeutics, New York Chicago, 2108.

[38] Jolles, S., Sewell, W.A. and Leighton, C. (2000) Drug-Induced Aseptic Meningitis: Diagnosis and Management. Drug Safety, 22, 215-216. https://doi.org/10.2165/00002018-200022030-00005

[39] Fredericks, C.M. Disorders of the Cerebellum and Its Connections. In: Disorders of Central Motor Control, Chapter 19, 445-466. https://pdfs.semanticscholar.org/dba1/cf02803299be6ebf11fe8bfea3ef03f67064.pdf

[40] WHO (2009) WHO Monographs on Selected Medicinal Plants. Volume 4, World Health Organization, WHO Press, Geneva. http://www.who.int/medicines/areas/traditional/SelectMonoVol4.pdf

[41] UNECE (2017) Globally Harmonized System of Classification and Labeling of Chemicals (GHS), GHS (Rev. 7). United Nations Economic Commission for Europe (UNECE), 1-534.

http://www.unece.org/fileadmin/DAM/trans/danger/publi/ghs/ghs_rev07/English/S T_SG_AC10_30_Rev7e.pdf 